\title{
Effectiveness and cost effectiveness of cardiovascular disease prevention in whole populations: modelling study
}

\author{
Pelham Barton reader in mathematical modelling ${ }^{1}$, Lazaros Andronis research fellow ${ }^{1}$, Andrew \\ Briggs $W R$ Lindsay chair in health policy and economic evaluation ${ }^{2}$, Klim McPherson visiting \\ professor of public health epidemiology ${ }^{3}$, Simon Capewell professor of clinical epidemiology ${ }^{4}$
}

${ }^{1}$ Health Economics Unit, Public Health Building, University of Birmingham, Birmingham B15 2TT, UK; ${ }^{2}$ Health Economics and Health Technology Assessment, University of Glasgow, Glasgow, UK; ${ }^{3} \mathrm{New}$ College, University of Oxford, Oxford OX1 2JD, UK; ${ }^{4} \mathrm{Public}$ Health Department, University of Liverpool, Liverpool L69 3GB, UK

\author{
Abstract \\ Objective To estimate the potential cost effectiveness of a \\ population-wide risk factor reduction programme aimed at preventing \\ cardiovascular disease. \\ Design Economic modelling analysis. \\ Setting England and Wales. \\ Population Entire population. \\ Model Spreadsheet model to quantify the reduction in cardiovascular \\ disease over a decade, assuming the benefits apply consistently for \\ men and women across age and risk groups.
}

Main outcome measures Cardiovascular events avoided, quality adjusted life years gained, and savings in healthcare costs for a given effectiveness; estimates of how much it would be worth spending to achieve a specific outcome.

Results A programme across the entire population of England and Wales (about 50 million people) that reduced cardiovascular events by just $1 \%$ would result in savings to the health service worth at least $£ 30 \mathrm{~m}$ (€34m; \$48m) a year compared with no additional intervention. Reducing mean cholesterol concentrations or blood pressure levels in the population by $5 \%$ (as already achieved by similar interventions in some other countries) would result in annual savings worth at least $£ 80 \mathrm{~m}$ to $£ 100 \mathrm{~m}$. Legislation or other measures to reduce dietary salt intake by $3 \mathrm{~g} /$ day (current mean intake approximately $8.5 \mathrm{~g} /$ day) would prevent approximately 30000 cardiovascular events, with savings worth at least $£ 40 \mathrm{~m}$ a year. Legislation to reduce intake of industrial trans fatty acid by approximately $0.5 \%$ of total energy content might gain around 570 000 life years and generate NHS savings worth at least $£ 230 \mathrm{~m}$ a year.

Conclusions Any intervention that achieved even a modest population-wide reduction in any major cardiovascular risk factor would produce a net cost saving to the NHS, as well as improving health. Given the conservative assumptions used in this model, the true benefits would probably be greater.

\section{Introduction}

Cardiovascular diseases (principally coronary heart disease and stroke) together account for more than 150000 deaths a year in the United Kingdom. ${ }^{1}$ Cardiovascular diseases affect more than five million people, and annual costs exceed $£ 30 \mathrm{bn}(€ 34 \mathrm{bn}$; $\$ 48 \mathrm{bn}){ }^{2}$ However, more than $80 \%$ of premature (at age $<75$ ) cardiovascular disease is avoidable. ${ }^{34}$

The UK government strategy for the primary prevention of cardiovascular disease therefore focuses on a dual approach. National Health Service (NHS) health checks to detect and treat people at high risk are underpinned by policies benefiting the entire population, such as smoke-free legislation and the progressive reduction in the salt content of processed food. ${ }^{56}$ In 2004 the Wanless report suggested that a more "fully engaged" population-wide prevention strategy might save $£ 36 \mathrm{bn}$ a year. ${ }^{7}$ Abelson estimated comparable savings in Australia. ${ }^{8}$ More recently, the Trust for America's Health calculated a six for one return on investment for population-wide approaches to prevention in the United States.'

Elsewhere, many studies have suggested that tobacco control programmes are cost saving. ${ }^{10}$ Likewise, dietary salt reduction policies consistently seem to be very cost effective, ${ }^{11}$ or even cost saving. ${ }^{12}{ }^{13}$ However, data on the economics of other population based dietary interventions, such as the eradication of trans fats or reduction of saturated fat, are much scarcer. ${ }^{10-15}$ The effectiveness and cost effectiveness of population based dietary approaches to prevention of cardiovascular disease in the UK are less clear. The Department of Health therefore asked 
the National Institute for Health and Clinical Excellence to develop guidance on a public health programme aimed at preventing cardiovascular disease in whole populations. To inform this programme, we built a generic economic model to estimate the comparative cost effectiveness of such interventions. After initial development and testing, we applied this model to two general scenarios involving small decreases in population levels of blood pressure or total cholesterol concentrations and to two specific legislative interventions aimed at reducing the dietary intake of salt and trans fats.

\section{Methods}

After consultation with stakeholders, we built a generic spreadsheet model quantifying a range of possible interventions, which could estimate cases of cardiovascular disease and deaths due to cardiovascular disease prevented or postponed, life years and quality adjusted life years (QALYs) gained, and cost savings to the NHS resulting from cases prevented or postponed. After initial development and testing, we applied this model to two general scenarios involving small decreases in blood pressure and total cholesterol concentration and to two specific examples of legislative interventions to reduce the dietary intakes of salt and trans fats.

\section{Model development}

We developed a spreadsheet model in four successive stages: costs, cases prevented, individual benefits, then aggregating the benefits.

\section{Determining NHS costs and QALYs lost for one case of cardiovascular disease}

For costing, we adapted the principles of the Sheffield prevention model, updating unit costs and otherwise inflating to $2008 .{ }^{16}$ These are detailed in the web appendix. All new costs and inflation indices came from Curtis. ${ }^{17}$

We estimated the expected lifetime costs, life years, and QALYs after a first cardiovascular event as a function of age and sex. Comparing these with life expectancy without an event then gave the loss in life years and QALYs from such an event. For example, we considered the case of a 65 year old man who developed stable angina. We combined life expectancy data from the government actuary's department with quality of life data from Sheffield to estimate a discounted quality adjusted life expectancy of 8.50 QALYs. ${ }^{16} \mathrm{We}$ used data from Ward et al to estimate lifetime treatment costs with stable angina of $£ 2338$ and a loss of 2.12 QALYs. ${ }^{16}$ We then did similar calculations for a 65 year old man having a first cardiovascular event to estimate lifetime treatment costs and QALYs lost. The range of cardiovascular events reflected the typical age dependent case mix. ${ }^{16} \mathrm{We}$ then repeated this process for men and women at all ages from 40 to 90 years (see appendix).

\section{Assessing pattern of cases of cardiovascular disease prevented or postponed for intervention of known effectiveness, using Framingham risk equation applied to single birth cohort}

We assessed the pattern of cases prevented or postponed by an intervention of known effectiveness. We used the Framingham risk equations to generate the expected pattern of first cardiovascular events according to the person's age, sex, and risk of cardiovascular disease. ${ }^{18}$

To estimate the effect of an intervention, we used a relative risk applied to the annual risk of a first cardiovascular event. This generated expected reductions in first cardiovascular events over a 10 year period. The appendix shows an example for a 65 year old man with a 10 year risk of cardiovascular disease of $12.5 \%$ and an intervention achieving an annual relative risk of 0.9 . We then did similar calculations for all men and women in 10 year age bands from 45 to 75 . The distribution of risk factors in 10 year age groups was based on the Joint British Societies' guidelines. ${ }^{19}$ For ease of modelling, we took the "under $10 \%$ " cardiovascular disease risk group at $7.5 \%$ and the "over 30\%" risk group at $32.5 \%$.

\section{Combining results from first two stages to estimate potential outcomes for single combination of age, sex, and risk}

We then combined the results of the first two stages to produce estimates of deaths prevented, life years gained, QALYs gained, and cost savings separately for each group. The appendix shows an illustrative example for an intervention with relative risk 0.9 applied to 65 year old men.

\section{Generating output for men and women of all ages, then aggregating results to give total estimated NHS costs and QALYs gained at level of entire England and Wales population of 50 million}

To reflect the nature of the risk equation and the assumptions needed, we conservatively estimated benefits from a reduction in the number of cases over a 10 year time horizon. We then expressed the output on an annual basis. We then aggregated the results across these distributions to give us expected outcomes for men and women of unknown cardiovascular disease risk in 10 year age bands.

We calculated the total population effects for 10 year age groups in England and Wales by using data from the Office for National Statistics. ${ }^{20}$ We then calculated the total population without cardiovascular disease eligible for primary prevention by subtracting the Sheffield estimate of the people with a history of cardiovascular disease from the population total. ${ }^{16}$ Scaling up the group results then provided the estimates for the total population (see appendix).

We used NICE's standard annual discount rate of 3.5\% for both costs and outcomes. We have converted total savings into annual equivalent savings across each of the 10 years, after allowing for the discounting applied. Full technical details of the model are available in the appendix and on the NICE website. ${ }^{21}$

\section{Results}

\section{Generic population-wide interventions}

Reducing the cardiovascular risk of the population by just $1 \%$ sustained over 10 years would prevent approximately 25000 new cases of cardiovascular disease and 3500 deaths from cardiovascular disease. This would gain around 98000 QALYs and would generate total (discounted) savings of approximately $£ 265 \mathrm{~m}$, equivalent to annual savings across the 10 years of the programme of approximately $£ 30 \mathrm{~m}$, compared with no additional intervention (table 1). Here, and elsewhere, a large part of the substantial gain in QALYs is due to the prevention of non-fatal events that strongly affect quality of life. The number of QALYs gained therefore exceeds the number of life years gained.

Reducing population blood pressure levels or total cholesterol concentrations by $5 \%$ would result in correspondingly larger health gains. Annual equivalent savings would be approximately 
$£ 100$ million for blood pressure (table 2 ) and $£ 80$ million for cholesterol (table 3).

\section{Specific interventions}

\section{Legislation to reduce salt intake}

Dietary salt intake in England and Wales averages approximately $8.5 \mathrm{~g} /$ day. A reduction of $3 \mathrm{~g} /$ day in salt intake represents a conservative estimate of the potential effects of specific legislation, based on the $6 \mathrm{~g}$ reduction achieved in Finland, Japan, and elsewhere. ${ }^{22}$ Reducing salt intake by $3 \mathrm{~g} /$ day might reduce mean population systolic blood pressure by approximately $2.5 \mathrm{~mm} \mathrm{Hg} .{ }^{23}$ This would equate to a $2 \%$ decrease in the risk reduction model. ${ }^{23}$ This would prevent approximately 4450 deaths from cardiovascular disease, with total discounted savings overall of approximately $£ 347 \mathrm{~m}$ over a decade, representing equivalent annual savings of approximately $£ 40 \mathrm{~m}$ (table 4). Any salt reduction intervention totalling up to $£ 40 \mathrm{~m}$ a year would therefore still be cost saving.

\section{Legislation to ban industrial fats}

Industrial trans fats account for approximately $0.8 \%$ of total UK dietary energy intake. ${ }^{23}$ Based on experience in Denmark, trans fat levels could be reduced by approximately $0.5 \%$ of total UK dietary energy intake. ${ }^{1524}$ This would reduce the relative risk of death from cardiovascular disease by approximately $6 \% .{ }^{25}$ Applying these benefits to the entire England and Wales population would prevent approximately 2700 deaths annually and thus gain 570000 life years, saving the equivalent of approximately $£ 235 \mathrm{~m}$ a year (table 5). An intervention costing up to $£ 230 \mathrm{~m}$ a year would therefore still be cost saving if it achieved the desired reduction in trans fats.

\section{Sensitivity analyses}

We did an extensive series of sensitivity analyses. In brief, savings occurred even when the background risk was reduced by $5 \%$ or $50 \%$. Corresponding increases of $5 \%$ and $50 \%$ are also shown for completeness in the web appendix.

\section{Discussion}

Our results strongly suggest that any policy intervention achieving even a $1 \%$ population-wide reduction in risk of cardiovascular disease can be expected to produce a net cost saving to the NHS, as well as decreasing losses in productivity and improving health. Only if a very large sum of money needs to be spent on implementing the legislation would this cease to be the case. Our findings are reassuringly consistent with analyses from the United States, Australia, and the UK Treasury. ${ }^{7-15}{ }^{26}$ Likewise, a five year campaign on salt reduction by the UK Food Standards Agency cost approximately $£ 15 \mathrm{~m}$ and achieved a reduction of $0.9 \mathrm{~g} /$ day in average salt intake. This was estimated to prevent approximately 6000 cardiovascular deaths a year, with estimated savings totalling some $£ 1.5 \mathrm{bn}$, or $£ 300 \mathrm{~m}$ a year. ${ }^{6}$ Furthermore, analyses of cohorts with lower cardiovascular risk show fewer cardiovascular events delayed to an older age and incurring substantially lower Medicare costs. ${ }^{27}$

The 5\% reductions modelled for systolic blood pressure and cholesterol concentration are entirely consistent with the actual falls achieved in regional programmes such as North Karelia, Stanford, and HeartBeat Wales. ${ }^{28}{ }^{29}$ Furthermore, much larger reductions in entire populations have been documented since the 1980s. For instance, cholesterol reductions of $22 \%$ in Finland, 14\% in Iceland, 10\% in Sweden, and 6\% in the United
States have been reported. ${ }^{30} 3132{ }^{33}$ Likewise, blood pressure reductions of 8\% in England and 6\% in Finland have been reported. ${ }^{29} 30$

Our $0.5 \%$ reduction in industrial trans fats represents a conservative estimate of what is possible, given past UK trends and recent Danish experience of successful eradication. ${ }^{34}$ Industrial trans fats have now been banned in five European countries: Denmark, Switzerland, Austria, Sweden, and Iceland. Manufacturers have adapted rapidly, easily, and with minimal costs. ${ }^{35}$ We would suggest that the UK is unlikely to be very different. Furthermore, important inequalities exist, given the very high consumption of trans fats recently reported in some disadvantaged groups (exceeding $6 \%$ of daily energy) ${ }^{35}$ Benefits in deprived communities might therefore be even larger.

\section{Strengths of analysis}

Our spreadsheet model allows a relative risk to be applied to each year's risk of primary cardiovascular disease in the population. It also allows percentage reductions in cholesterol concentration and systolic blood pressure to be considered separately for men and women. The model is designed to be transparent and involves relatively few assumptions, each of which can be easily tested. Furthermore, the estimates are based on a series of conservative assumptions, so the true benefits are likely to be substantially larger.

We quantified only NHS savings. Net social savings will clearly be much larger. The model focuses on primary prevention of cardiovascular disease. All population-wide risk factor reduction programmes considered in this report would also benefit the five million patients with recognised cardiovascular disease in the UK. ${ }^{36}{ }^{37}$ Substantial reductions in diabetes, many common cancers, and other chronic diseases would also occur. ${ }^{37}$

This simple model assumed a uniform distribution of burden and benefit across social groups. In fact, deprived groups have disproportionately more disease and would thus gain more from population-wide risk factor reductions. Absolute inequalities would also be decreased. ${ }^{38}$

This is not simply a cost of illness study. It is a modelling study that shows the range of possible cost savings and QALY benefits from a range of plausible interventions. It therefore allows an upper limit to be placed on the cost at which any such intervention would be worthwhile. Greater complexity in the model might lead to additional precision in the results. However, we suggest that this additional precision might make surprisingly little difference to the key policy decisions.

The sensitivity analyses were reassuring and suggested that using a different risk "engine" to drive the model would have a relatively modest effect. The model is based on the original Framingham equations and the same risk score as the Joint British Societies' guidelines, which is widely used and understood. It also reflects the model that was presented to the NICE Programme Development Group to assist in their deliberations and inform their subsequent key recommendations. ${ }^{35}$

\section{Limitations of analysis}

Our conclusions are clearly subject to several important limitations reflecting the nature of the model. Apart from the increased mortality immediately after a first non-fatal primary cardiovascular event, we made no attempt to consider recurrent events or subsequent deaths. The estimates of deaths avoided, life years gained, and cost savings are thus likely to be underestimates, making the analysis somewhat conservative. A 
further limitation is the 10 year time frame for prevention of cases; gains over a lifetime would clearly be greater.

The analysis was pragmatically limited to people aged between 40 and 79 years at the time of the intervention. However, given the very high rates of cardiovascular events in people aged over 80 , substantial additional benefits might be expected. Our interventions assumed relatively uniform effects across age and risk groups by definition. However, the subsequent changes in specific risk factors included age gradients and considered men and women separately.

In this study, the counterfactual (no intervention) implicitly assumes that the population risk of cardiovascular disease would remain constant. However, there may be a "natural" increase or decrease in cardiovascular risk without population-wide interventions. Modest changes could also follow targeted interventions in subgroups. Either of these scenarios might affect future costs and QALYs.

Finally, this initial modelling lacks a full probabilistic sensitivity analysis, because many essential data inputs (such as the distribution of risk factors in the population) were readily available only as point estimates. However, the range of changes in risk factors and their effects quantified in the results tables and web appendices provide a satisfactory and rigorous sensitivity analysis. Future studies might usefully include a full probabilistic sensitivity analysis to formally test the uncertainties inherent in the various modelling assumptions.

\section{Implications of findings}

We estimated that a $1 \%$ reduction in the relative risk of cardiovascular disease would generate discounted NHS savings of approximately $£ 30 \mathrm{~m}$ a year in England and Wales, compared with no additional intervention, This estimate is considerably less than $1 \%$ of the $£ 7 \mathrm{bn}$ healthcare costs calculated by Luengo-Fernández et al. ${ }^{2}$ However, this again highlights the conservative approach taken in our modelling.

In terms of opportunity cost, any programme that reduces the rate of death from cardiovascular disease by $1 \%$ is cost effective up to costs of $£ 30 \mathrm{~m}$, as long as no alternative programme causes a bigger reduction at the same costs or the same reduction at lower costs. Varying the underlying Framingham risk equation to include newer values such as QRISK $_{2}$ will also be useful. ${ }^{39}$ However, the resulting changes are likely to be small. Furthermore, subsequent research should ensure that such models remain up to date, accessible, and credible. A better quantification of our understanding of causal pathways for cardiovascular disease will be challenging but important.

An important factor is the feasibility of population-wide dietary changes-for instance, in salt consumption. Cultural aspects are important in some countries, such as salted fish in Portugal and salted vodka further east. However, most populations now live in a global economy. We eat what is available, affordable, and acceptable. In our UK study population, that means that more than $80 \%$ of consumed salt is concealed in processed food. ${ }^{22}{ }^{35}$ In the UK, media campaigns and voluntary agreements with the food industry have already achieved a $1 \mathrm{~g}$ reduction in salt consumption. We therefore suggest that a $3 \mathrm{~g}$ reduction might be entirely feasible by using more muscular regulatory approaches. The $6 \mathrm{~g}$ reductions in Finland and Japan were achieved in spite of cultural traditions and resistance from the industry. ${ }^{22} 29$ Furthermore, reductions of 5-10\% in the salt content of any specific food during one year are simply not noticed by most consumers. This is because human taste buds adapt very quickly. Salt has already been substantially decreased in the UK and several other countries, with no evidence of widespread compensation by consumers. ${ }^{35}$

This paper does not detail the specific costs of particular programmes. It is making a more general argument. Given the benefits in terms of increased health and reduced healthcare costs, the sorts of programmes we have seen work in other countries must surely also be cost effective here.

\section{Conclusions}

Our model is relatively simple and transparent with clear limitations. However, the cumulative conservative assumptions mean that the benefits and cost savings are almost certainly underestimated. The findings are reassuringly consistent with results from very different methods in the United States, Australia, and the UK Treasury. ${ }^{7-9} 26{ }^{27} 40$ Population-wide prevention interventions seem to be both powerful and cost saving.

Contributors: $\mathrm{PB}$ and $\mathrm{LA}$ designed and implemented the model with advice from $\mathrm{KMcP}, \mathrm{AB}$, and $\mathrm{SC}$. SC drafted the first and final versions of the manuscript and led the submission and revision process. All authors contributed to the drafting and approval of the final manuscript. $P B$ is the guarantor.

Funding: PB and LA were funded by NICE. KMcP, AB, and SC were all members of the NICE Programme Development Group on cardiovascular disease prevention in populations. However, the conclusions do not necessarily reflect official NICE views. West Midlands Health Technology Assessment Collaboration (WMHTAC) and Peninsula Technology Appraisal Group (PenTAG) were funded to provide support to the NICE Centre for Public Health Excellence (CPHE).

Competing interests: All authors have completed the Unified Competing Interest form at www.icmje.org/coi_disclosure.pdf (available on request from the corresponding author) and declare no support from any organisation apart from NICE for the submitted work. PB and LA were funded by NICE. WMHTAC and Peninsula Technology Appraisal Group (PenTAG) were funded to provide support to the NICE CPHE. KMcP, $A B$, and $S C$ were all members of the NICE Programme Development Group on CVD prevention in populations.

Ethical approval: Not needed.

Data sharing: No additional data available.

1 British Heart Foundation. Heart statistics. 2011. www. Heartstats.org.uk.

2 Luengo-Fernández R, Leal J, Gray A, Petersen S, Rayner M. Cost of cardiovascular diseases in the United Kingdom. Heart 2000;92:1384-9.

3 Yusuf S, Hawken S, Ounpuu S, Dans T, Avezum A, Lanas F, et al. Effect of potentially modifiable risk factors associated with myocardial infarction in 52 countries (the INTERHEART study): case-control study. Lancet 2004;364:937-52.

4 Capewell S, Ford ES, Croft JB, Critchley JA, Greenlund KJ, Labarthe DR. Cardiovascular risk factor trends in the US population and options for reducing future CHD mortality. Bull World Health Organ 2010;88:120-30.

5 Department of Health. Putting prevention first-vascular checks: risk assessment and management. DH, 2008.

6 Food Standards Agency. Dietary sodium levels surveys. 2008. www.food.gov.uk/science/ dietarysurveys/urinary.

dietarysurveys/urinary.

8 Abelson P. Returns on investment in public health: an epidemiological and economic analysis prepared for the Department of Health and Ageing. Department of Health and Ageing, Australia, 2001.

9 Trust for America's Health. Prevention for a healthier America: investments in disease prevention yield significant savings, stronger communities. Trust for America's Health, prevention. 2008.

10 Institute of Medicine. Promoting cardiovascular health in the developing world: a critical challenge to achieve global health. National Academies Press, 2010.

11 Murray CJ, Lauer JA, Hutubessy RC, Niessen L, Tomijima N, Rodgers A, et al. Effectiveness and costs of interventions to lower systolic blood pressure and cholesterol: a global and regional analysis on reduction of cardiovascular-disease risk. Lancet 2003:361:717-25.

12 Bibbins-Domingo K, Chertow GM, Coxson PG, Moran A, Lightwood JM, Pletcher MJ, et al. Projected effect of dietary salt reductions on future cardiovascular disease. $N$ Engl $J$ Med 2010;362:590-9.

13 Smith-Spangler CM, Juusola JL, Enns EA, Owens DK, Garber AM. Population strategies to decrease sodium intake and the burden of cardiovascular disease. Ann Intern Med 2010;4819:152-8. 


\section{What is already known on this topic}

Population-wide prevention programmes, such as salt reduction, trans fat eradication, or smoke-free legislation seem to be very effective for preventing cardiovascular disease

Studies in the United States and Australia suggest that as well as reducing cardiovascular events and deaths, such programmes may also be cost saving

\section{What this study adds}

A national programme reducing population cardiovascular risk by $1 \%$ would prevent approximately 25000 cardiovascular disease cases and generate public sector savings of about $£ 30 \mathrm{~m}$ a year

Reducing mean population cholesterol or blood pressure levels by $5 \%$ (as already achieved in some other countries) would result in annual savings of approximately $£ 80 \mathrm{~m}$ or $£ 100 \mathrm{~m}$

Legislation or other measures to reduce dietary salt intake by $3 \mathrm{~g} /$ day or industrial trans fatty acid intake by approximately $0.7 \%$ of total energy content would save about $£ 40 \mathrm{~m}$ or $£ 230 \mathrm{~m}$ a year

14 Kristiansen IS, Eggen AE, Thelle DS. Cost effectiveness of incremental programmes for lowering serum cholesterol concentration. BMJ 1991;302:1119-22.

15 Mozaffarian D, Stampfer MJ. Removing industrial trans fat from foods. $B M J$ 2010;340:c1826.

16 Ward S, Lloyd Jones M, Pandor A, Holmes M, Ara R, Ryan A, et al. Statins for the prevention of coronary events: technology assessment report commissioned by the HTA Programme on behalf of the National Institute for Clinical Excellence. 2011. www.nice. org.uk/nicemedia/live/11563/33142/33142.pdf.

17 Curtis L. Unit costs of health and social care 2009. Personal Social Services Research Unit, University of Kent, 2010

18 Anderson KM, Wilson PW, Odell PM, Kannel WB. An updated coronary risk profile: a statement for health professionals. Circulation 1991;83:356-62.

19 British Cardiac Society, British Hypertension Society, Diabetes UK, HEART UK, Primary Care Cardiovascular Society, Stroke Association. JBS2: Joint British Societies' guidelines on prevention of cardiovascular disease in clinical practice. Heart2005;91(suppl V) :v1-52.

20 Office of National Statistics. Population estimates for UK, England and Wales, Scotland and Northern Ireland—current datasets. 2010. www.statistics.gov.uk/statbase/Product. asp?vInk=15106.

21 Barton P, Andronis L. Prevention of cardiovascular disease at population level: modelling strategies for primary prevention of cardiovascular disease. Report to NICE. 2009. www. nice.org. uk/guidance/index.jsp?action $=$ download $\& 0=45710$.

$22 \mathrm{He}$ FJ, MacGregor GA. A comprehensive review on salt and health and current experience of worldwide salt reduction programmes. J Hum Hypertens 2009;23:363-84.

23 Food Standards Agency. Low income diet and nutrition survey. 2007. www.food.gov.uk science/dietarysurveys/lidnsbranch/.

24 Mozaffarian D, Aro A, Willett W. Health effects of trans-fatty acids: experimental and observational evidence. Eur J Clin Nutr 2009:63:S5-21.

25 Vartiainen E, Laatikainen, Peltonen P, Juolevi A, Männistö S, Sundvall J, et al. Thirty-five-year trends in cardiovascular risk factors in Finland. Int $\mathrm{J}$ Epidemiol 2010;39:504-18.

26 Vos T, Carter R, Barendregt J, Mihalopoulos C, Veerman JL, Magnus A, et al, for the ACE-Prevention Team. Assessing cost-effectiveness in prevention (ACE-Prevention): final report. University of Queensland, Brisbane and Deakin University, 2010.

27 Daviglus ML, Liu K, Greenland P, Dyer AR, Garside DB, Manheim L, et al. Benefits of a favorable cardiovascular risk-factor profile in middle age with respect to Medicare costs. N Engl J Med 1998;339:1122-9.
28 Tudor-Smith C, Nutbeam D, Moore L, Catford J. Effects of the Heartbeat Wales programme over five years on behavioural risks for cardiovascular disease: quasi-experimental comparison of results from Wales and a matched reference area. BMJ 1998;316;818-22.

29 Laatikainen T, Critchley J, Vartiainen E, Salomaa V, Ketonen M, Capewell S. Explaining the decline in CHD mortality in Finland between 1982 and 1997. Am J Epidemiol 2005;162:764-73.

30 Aspelund T, Gudnason V, Magnusdottir BT, Andersen K, Sigurdsson G, Thorsson B, et al. Analysing the large decline in coronary heart disease mortality in the Icelandic population aged 25-74 between the years 1981 and 2006. PLOS One 2010;5:e13957.

31 Björck L, Rosengren A, Bennett K, Lappas G, Capewell S. Modelling the decreasing CHD mortality in Sweden between 1986 and 2002. Eur Heart J 2009;30:1046-56.

32 Ford ES, Ajani UA, Croft JB, Critchley JA, Labarthe DR, Kottke TE, et al. Explaining the decrease in US deaths from coronary disease, 1980-2000. N Engl J Med 2007:356:2388-98.

33 Unal B, Critchley JA, Capewell S. Explaining the decline in coronary heart disease mortality in England and Wales between 1981 and 2000. Circulation 2004;109:1101-7.

34 Stender S, Dyerberg J, Bysted A, Leth T, Astrup A. A trans world journey. Atheroscler Suppl 2006;7:47-52.

35 National Institute for Health and Clinical Excellence. Prevention of cardiovascular disease at population level. NICE, 2010. (Public health guidance 25.)

36 Capewell S, Allender S, Critchley J, Lloyd-Williams F, O'Flaherty M, Rayner M, et al. Modelling the UK burden of cardiovascular disease to 2020: a research report for the Cardio \& Vascular Coalition and the British Heart Foundation. British Heart Foundation, 2008. (Available at www.bhf.org.uk/cvc/working_groups/modelling_burden_of_cvd.aspx.) 37 Strategy Unit. Food matters: towards a strategy for the 21 st century. Cabinet Office, 2008.

38 Capewell S, Graham H. Will cardiovascular disease prevention widen health inequalities? PLoS Med 2010;7:e1000320.

39 Collins G, Altman D. An independent and external validation of QRISK2 cardiovascular disease risk score: a prospective open cohort study. BMJ 2010;340:c2442.

40 Catford J. Advancing the "science of delivery" of health promotion: not just the "science of discovery". Health Promot Int 2009;24:1-5.

Accepted: 13 May 2011

Cite this as: $B M J 2011 ; 343: \mathrm{d} 4044$ 


\section{Tables}

Table 1 | Discounted outcomes for intervention achieving given relative risk reduction sustained over 10 years

\begin{tabular}{|c|c|c|c|c|c|c|}
\hline $\begin{array}{l}\text { Relative risk } \\
\text { reduction }\end{array}$ & $\begin{array}{c}\text { Cases prevented } \\
(\times 1000)\end{array}$ & $\begin{array}{l}\text { Deaths prevented } \\
(\times 1000)\end{array}$ & $\begin{array}{l}\text { Life years gained } \\
\qquad \times 1000)\end{array}$ & $\begin{array}{l}\text { QALYs gained } \\
(\times 1000)\end{array}$ & Total savings (£m) & $\begin{array}{c}\text { Annual equivalent } \\
\text { savings (£m) }\end{array}$ \\
\hline 0.001 & 2 & 0.3 & 7 & 10 & 26 & 3 \\
\hline 0.005 & 12 & 1.7 & 37 & 49 & 132 & 15 \\
\hline 0.01 & 25 & 3.5 & 74 & 98 & 265 & 31 \\
\hline 0.02 & 50 & 7.0 & 149 & 197 & 530 & 62 \\
\hline 0.03 & 75 & 10 & 224 & 295 & 796 & 93 \\
\hline 0.04 & 100 & 14 & 299 & 394 & 1063 & 123 \\
\hline 0.05 & 125 & 18 & 374 & 493 & 1330 & 154 \\
\hline 0.06 & 150 & 21 & 449 & 592 & 1597 & 186 \\
\hline 0.07 & 175 & 25 & 524 & 692 & 1865 & 217 \\
\hline 0.08 & 201 & 28 & 600 & 791 & 2133 & 248 \\
\hline 0.09 & 226 & 32 & 675 & 891 & 2402 & 279 \\
\hline 0.1 & 251 & 35 & 751 & 990 & 2671 & 310 \\
\hline 0.15 & 378 & 53 & 1132 & 1492 & 4024 & 467 \\
\hline 0.2 & 507 & 71 & 1516 & 1997 & 5389 & 626 \\
\hline 0.25 & 637 & 89 & 1903 & 2507 & 6766 & 786 \\
\hline 0.3 & 768 & 108 & 2294 & 3021 & 8155 & 947 \\
\hline 0.35 & 900 & 126 & 2689 & 3540 & 9557 & 1110 \\
\hline 0.4 & 1033 & 145 & 3088 & 4062 & 10971 & 1275 \\
\hline 0.45 & 1168 & 164 & 3490 & 4589 & 12397 & 1440 \\
\hline 0.5 & 1304 & 183 & 3895 & 5121 & 13836 & 1607 \\
\hline
\end{tabular}

QALY=quality adjusted life year. 
Table 2| Discounted outcomes for intervention with given percentage reduction in systolic blood pressure sustained over 10 years

\begin{tabular}{|c|c|c|c|c|c|c|}
\hline $\begin{array}{l}\text { Percentage reduction in } \\
\text { systolic blood pressure }\end{array}$ & $\begin{array}{l}\text { Cases prevented } \\
\qquad(\times 1000)\end{array}$ & $\begin{array}{l}\text { Deaths prevented } \\
\qquad(\times 1000)\end{array}$ & $\begin{array}{l}\text { Life years gained } \\
\qquad(\times 1000)\end{array}$ & $\begin{array}{l}\text { QALYs gained } \\
(\times 1000)\end{array}$ & Total savings ( $(\mathrm{m})$ & $\begin{array}{c}\text { Annual equivalent } \\
\text { savings }(\Sigma m)\end{array}$ \\
\hline 0.5 & 8 & 1.1 & 24 & 33 & 86 & 10 \\
\hline 1 & 16 & 2.2 & 48 & 65 & 173 & 20 \\
\hline 1.5 & 24 & 3.3 & 72 & 98 & 260 & 30 \\
\hline 2 & 32 & 4.4 & 96 & 131 & 347 & 40 \\
\hline 2.5 & 40 & 5.5 & 121 & 164 & 435 & 50 \\
\hline 3 & 48 & 6.7 & 145 & 197 & 522 & 61 \\
\hline 3.5 & 57 & 7.8 & 169 & 230 & 610 & 71 \\
\hline 4 & 65 & 8.9 & 194 & 263 & 699 & 81 \\
\hline 4.5 & 73 & 10.0 & 219 & 296 & 787 & 91 \\
\hline 5 & 81 & 11.2 & 243 & 330 & 876 & 102 \\
\hline
\end{tabular}

QALY=quality adjusted life year. 
Table 3| Discounted outcomes for intervention with given percentage reduction in cholesterol concentration sustained over 10 years

\begin{tabular}{|c|c|c|c|c|c|c|}
\hline $\begin{array}{l}\text { Percentage reduction } \\
\text { in cholesterol }\end{array}$ & $\begin{array}{l}\text { Cases prevented } \\
\qquad(\times 1000)\end{array}$ & $\begin{array}{l}\text { Deaths prevented } \\
\qquad(\times 1000)\end{array}$ & $\begin{array}{l}\text { Life years gained } \\
\qquad(\times 1000)\end{array}$ & $\begin{array}{l}\text { QALYs gained } \\
\qquad(\times 1000)\end{array}$ & Total savings $(\mathbf{E m})$ & $\begin{array}{c}\text { Annual equivalent } \\
\text { savings }(\mathrm{Em})\end{array}$ \\
\hline 0.5 & 6 & 0.9 & 19 & 26 & 68 & 8 \\
\hline 1 & 13 & 1.7 & 38 & 51 & 136 & 16 \\
\hline 1.5 & 19 & 2.6 & 57 & 77 & 205 & 24 \\
\hline 2 & 25 & 3.5 & 76 & 103 & 274 & 32 \\
\hline 2.5 & 32 & 4.4 & 95 & 129 & 343 & 40 \\
\hline 3 & 38 & 5.3 & 114 & 155 & 412 & 48 \\
\hline 3.5 & 45 & 6.1 & 134 & 181 & 481 & 56 \\
\hline 4 & 51 & 7.0 & 153 & 208 & 551 & 64 \\
\hline 4.5 & 58 & 7.9 & 172 & 234 & 621 & 72 \\
\hline 5 & 64 & 8.8 & 192 & 260 & 691 & 80 \\
\hline
\end{tabular}

QALY=quality adjusted life year. 
Table 4| Discounted estimates of total population effects from reduction of $3 \mathrm{~g} /$ day in salt intake sustained over 10 years, by age and sex

\begin{tabular}{|c|c|c|c|c|c|c|}
\hline Age groups (years) & $\begin{array}{l}\text { Cases prevented } \\
\qquad(\times 1000)\end{array}$ & $\begin{array}{l}\text { Deaths prevented } \\
\qquad(\times 1000)\end{array}$ & $\begin{array}{l}\text { Life years gained } \\
\qquad(\times 1000)\end{array}$ & $\begin{array}{l}\text { QALYs gained } \\
\qquad(\times 1000)\end{array}$ & Total savings (£m) & $\begin{array}{l}\text { Annual equivalent } \\
\text { savings ( }(\mathrm{m})\end{array}$ \\
\hline \multicolumn{7}{|l|}{ Men: } \\
\hline $40-49$ & 4.4 & 0.51 & 12 & 21 & 47 & 5 \\
\hline $50-59$ & 4.9 & 0.71 & 16 & 21 & 53 & 6 \\
\hline $60-69$ & 4.8 & 0.74 & 15 & 17 & 49 & 6 \\
\hline 70-79 & 3.1 & 0.45 & 7 & 8 & 28 & 3 \\
\hline \multicolumn{7}{|l|}{ Women: } \\
\hline $40-49$ & 4.0 & 0.39 & 11 & 19 & 48 & 6 \\
\hline $50-59$ & 3.8 & 0.51 & 13 & 18 & 46 & 5 \\
\hline $60-69$ & 3.9 & 0.64 & 14 & 16 & 45 & 5 \\
\hline 70-79 & 3.2 & 0.48 & 9 & 10 & 31 & 4 \\
\hline Totals & 32.2 & 4.43 & 96 & 131 & 347 & 40 \\
\hline
\end{tabular}

Any apparent anomalies with addition are due to rounding effects.

QALY=quality adjusted life year. 
Table 5| Discounted estimates of total population effects from intervention based on legislation against trans fats sustained over 10 years, by age and sex

\begin{tabular}{|c|c|c|c|c|c|c|}
\hline Age groups (years) & $\begin{array}{l}\text { Cases prevented } \\
(\times 1000)\end{array}$ & $\begin{array}{l}\text { Deaths prevented } \\
\qquad(\times 1000)\end{array}$ & $\begin{array}{l}\text { Life years gained } \\
\qquad(\times 1000)\end{array}$ & $\begin{array}{l}\text { QALYs gained } \\
(\times 1000)\end{array}$ & Total savings $(£ \mathrm{~m})$ & $\begin{array}{l}\text { Annual equivalent } \\
\text { savings ( }(\mathrm{m})\end{array}$ \\
\hline \multicolumn{7}{|l|}{ Men: } \\
\hline $40-49$ & 23 & 2.7 & 64 & 107 & 243 & 28 \\
\hline $50-59$ & 30 & 4.3 & 96 & 129 & 322 & 37 \\
\hline $60-69$ & 33 & 5.1 & 100 & 119 & 335 & 39 \\
\hline $70-79$ & 23 & 3.3 & 51 & 57 & 200 & 23 \\
\hline \multicolumn{7}{|l|}{ Women: } \\
\hline $40-49$ & 19 & 1.9 & 53 & 92 & 234 & 27 \\
\hline $50-59$ & 20 & 2.7 & 68 & 94 & 239 & 28 \\
\hline $60-69$ & 23 & 3.7 & 82 & 95 & 261 & 30 \\
\hline $70-79$ & 21 & 3.1 & 58 & 61 & 199 & 23 \\
\hline Totals & 191 & 26.8 & 571 & 754 & 2033 & 235 \\
\hline
\end{tabular}

QALY=quality adjusted life year.

Any apparent anomalies with addition are due to rounding effects. 